\title{
Population genetic structure of the Japanese eel Anguilla japonica in the northwest Pacific Ocean: evidence of non-panmictic populations
}

\author{
Mei-Chen Tseng ${ }^{1,4}$, Wann-Nian Tzeng ${ }^{2}$, Sin-Che Lee ${ }^{3, *}$ \\ ${ }^{1}$ Institute of Zoology and ${ }^{2}$ Institute of Fisheries Sciences, National Taiwan University, Taipei 106, Taiwan \\ ${ }^{3}$ Department of Life Science, Tunghai University, Taichung 407, Taiwan \\ ${ }^{4}$ Present address: Department of Aquaculture, Pingtung University of Science and Technology, Pingtung 912, Taiwan
}

\begin{abstract}
The catadromous Japanese eel has an unusual life history. Controversy remains, however, as to whether its population structure is characterized by panmixia or genetic differentiation. Migration patterns are considered an important factor in determining a species' population structure. Eight polymorphic microsatellite loci were used as genetic markers through which we were able to reject the null hypothesis of panmixia. Slight genetic differentiation between these populations was determined by Wright's and Slatkin's fixation indices, $F_{\mathrm{ST}}$ and $R_{\mathrm{ST}}$ statistics adjusted using Bonferroni's correction. Although isolation-by-distance is often observed in marine species, the present result is thought to follow the member-vagrant migratory hypothesis. The metapopulation model fits the elver recruitment strategy according to results of the high probability of assignment test. The UPGMA tree showed the Japanese eel populations as being divided into 2 groups: a low-latitude group (Shantou in South China, and Tanshui and Fangliao in Taiwan) and a high-latitude group (Mikawa Bay in Japan, Daecheon-myon in Korea, and the Yalu River and Hangzhou in Northeast China). Temporal genetic variations indicate that most progeny return to similar habitats where their ancestors formerly resided. There was a high correlation (AMOVA; $\mathrm{p}<0.05$ ) when the Japanese eel was divided into the 2 management units (high- and low-latitude groups). These units will be useful when applied to fisheries conservation and management in the northwestern Pacific Ocean.
\end{abstract}

KEY WORDS: Catadromous eel · Fisheries management units · Genetic differentiation · Membervagrant model $\cdot$ Microsatellites

\section{INTRODUCTION}

Diadromous fish move predictably between fresh and saltwater at relatively fixed periods in their life history. Many are commercially important, but their life histories and population structures are still not well known. As the catadromous eels of Anguilla have an interesting life history of spawning in the sea and growing up in rivers, many studies of their population genetics have been carried out. During the last 3 decades, these studies have attempted to determine whether conspecific eels from different freshwater localities are panmictic or if they represent different populations.

Although the population genetic structures of Anguilla anguilla, A. japonica, and A. rostrata have been intensively studied, controversy still exists as to whether these species are made up of a single panmictic population or multiple geographically based populations. For $A$. anguilla, protein electrophoresis and sequencing of the mitochondrial DNA (mtDNA) control region support the hypothesis that eels from European and North African rivers belong to a panmictic population (De Ligny \& Pantelouris 1973, Lintas et al. 1998, 
Avise 2003). Similar conclusions were reached for A. rostrata and A. japonica (Avise et al. 1986, Sang et al. 1994, Ishikawa et al. 2001). Although results derived from both nuclear and cytoplasmic markers have supported the panmictic hypothesis for the genetic structure of Anguilla eels, several studies have challenged this opinion. Slight genetic differentiation among 13 samples of European eels from the North Atlantic, the Baltic Sea, and Mediterranean Sea basins refutes the panmictic population hypothesis (Wirth \& Bernatchez 2001). However, A. japonica on the western Pacific fringe otherwise exhibits clear geographic clines when using NADP-isocitrate dehydrogenase (IDHP) and 6-phosphogluconate dehydrogenase (PGDH) allozyme loci as markers (Chan et al. 1997). A migration time-lag from various parts of different continents to spawning grounds west of the Mariana Islands is hypothesized as being a reason for the formation of this cline. The same results as applied to aging, using otoliths at metamorphosis and estimation of arrival times at estuaries, were determined from otolith increments; e.g. changes in the growth-line width and the strontium/calcium ratio further subdivide geographic populations of Japanese eel (Cheng \& Tzeng 1996).

Anguilla japonica is a temperate freshwater eel distributed in the rivers of northeastern Asian countries including Taiwan, China, Japan, and Korea (Tesch 1977). The leptocephali hatch in spawning grounds presumably located at deep offshore grounds to the west of the Mariana Islands at $15^{\circ} \mathrm{N}, 140^{\circ} \mathrm{E}$ (Tsukamoto 1992). They then drift westerly with the North Equatorial Current. When approaching the continental shelf of the Philippines, they continue to move northwards to join the Kuroshio Current by the aid of Ekman transport. Once the leptocephali metamorphose into the glass eel stage, they leave the strong Kuroshio Current journeying to estuaries where they continue to grow as elvers. In the course of their upstream migration, elvers grow to yellow eels which spend the next 5 to $10 \mathrm{yr}$ in freshwater rivers (Tzeng 1985). Once eels attain sexual maturity, they migrate downstream toward the deep sea for spawning (Tesch 1977).

The extremely compressed willow-like body shape facilitates the long-distance dispersion of leptocephali by ocean currents. Accordingly, metamorphosis times and migration patterns are considered important factors in determining the population structure of the Japanese eel. Opinions regarding the migratory route of Japanese eels, however, are diverse (Sang et al. 1994, Cheng \& Tzeng 1996, Ishikawa et al. 2001).

Two migration models of freshwater eels have been proposed. The panmictic model suggests that adult eels (e.g. the American eel, Anguilla rostrata) from different nursery grounds randomly mate in a common spawning ground, with their juveniles reaching estuar- ies at random after metamorphosis (Avise et al. 1986, Wirth \& Bernatchez 2003). The isolation model assumes that adult eels grow in separate freshwater habitats and spawn in separate breeding grounds at different times. These freshly hatched leptocephali are carried back to their respective parents' freshwater nursery habitats by the aid of currents. For A. marmorata, this model involves different migration loops over the western Pacific Ocean which may result in genetic differentiation (Ishikawa et al. 2004).

A recent hypothesis, 'the member-vagrant model', examined the role of ecological processes in determining the genetic patterns of marine species (Sinclair \& Iles 1988). Members are the fittest individuals, i.e. those juveniles recruited to appropriate habitats shared by adults. Vagrants are individuals which disperse to new habitats with an ancestry different from the nursery. Although larvae have greater dispersal ability to find new habitats, their lives may too short before they become adults. This hypothesis has been corroborated by ecological and genetic studies of populations of the Atlantic herring Clupea harengus, anadromous rainbow smelt Osmerus mordax, and European eel Anguilla anguilla (Iles \& Sinclair 1982, Fortier \& Gagne 1990, Bernatchez \& Martin 1996, Maes \& Volckaert 2002).

A metapopulation is described an assemblage of interacting individuals, and it seems an apt term for an assemblage of spatially delimited local populations that are coupled by a few degrees of migration (Hanski 1994, Gaggiotti 1996). However, because the population structure indicates slight but significant genetic differentiation among populations, incomplete isolation among populations may be discovered due to stray recruitment. However, this seems to be suggested for the European eel (Maes \& Volckaert 2002).

An approach to studying metapopulations is to analyze patterns of the presence or absence of organisms in relation to landscape characteristics (Sjögren-Gulve 1994). An assignment test was developed to determine the origin of particular individuals. This test assigned individuals to populations on the basis of their genotypes, while simultaneously estimating population allelic frequencies (Pritchard et al. 2000).

The Japanese eel provides a prime model for studying the spatial and temporal population structure of catadromous eels in the northwestern Pacific Ocean. Highly polymorphic microsatellites encoded by selective neutral nuclear loci have recently been used to investigate the genetic structure of populations, including many aquatic species for which it is difficult to tag individuals (Yu et al. 2002). The purpose of this study was to test the panmictic population hypothesis using 8 microsatellite loci and to clarify whether the migration model fits what is known about Japanese eel elvers. 


\section{MATERIALS AND METHODS}

Sample. In total, 328 Anguilla japonica elvers were caught alive in the winter of 1999 and spring of 2000 from 7 locations throughout their range in northeastern Asia. Collecting locations included Tanshui and Fangliao in Taiwan; the Yalu River, Hangzhou, and Shantou in China; Mikawa Bay in Japan; and Daecheon-myon in Korea (Table 1 \& Fig. 1). In all, 88 replicate yearly samples were collected separately from Tanshui and Fangliao in 1997 and 1990, respectively. All specimens were preserved in $95 \%$ ethanol prior to DNA extraction.

DNA extraction. Genomic DNA was isolated and purified from muscle tissue; the ethanol was removed by evaporation before treatment. A piece of muscle weighing $500 \mathrm{mg}$ was digested in $1 \mathrm{ml}$ of lysis buffer (10 mM Tris- $\mathrm{HCl}, \mathrm{pH}$ 8.0, $2 \mathrm{mM}$ ethylene diamine tetra-acetic acid [EDTA], $10 \mathrm{mM} \mathrm{NaCl}, 1 \%$ sodium dodecyl sulfate [SDS], $10 \mathrm{mg} \mathrm{ml}^{-1}$ dithiothreitol [DTT]) and $55 \mu$ l of proteinase $\mathrm{K}\left(0.5 \mathrm{mg} \mathrm{ml}^{-1}\right)$ before the DNA extraction (Kocher et al. 1989). DNA was precipitated with $95 \%$ ethanol, washed with $70 \%$ ethanol, airdried, and then dissolved in TE buffer (10 mM Tris- $\mathrm{HCl}$ [pH 8.0], 1 mM EDTA) (Sambrook et al. 1989). Genomic DNA was quantified and diluted to a working concentration of $1 \mathrm{ng} \mu \mathrm{l}^{-1}$.

PCR and genotyping. Eight microsatellite loci were screened from the Anguilla japonica genome including $6(\mathrm{GT})_{\mathrm{n}}(M S-1, M S-3, M S-4, M S-5, M S-7$, and $M S-8)$ and $2(\mathrm{GA})_{\mathrm{n}}(M S-2$ and $M S-6)$ loci. The MS-1 to 6 microsatellite sequences on EMBL, under the accession numbers AJ297599 AJ297603 and AJ297605, were described previously (Tseng et al. 2001). The primers were adjusted based on the flanking regions of 6 microsatellite sequences to avoid null alleles. $M S-7$ (forward primer: 5'-AGTAAAGAGTCCCACGCATTC-3'; reverse primer: 5'-AAGGTGGATTTTTGCTGGCTC-3') and $M S-8$ (forward primer: 5'-AGGCTGAAGTGAGTATGCTCAG-3'; reverse primer: 5'-AGATATGGAAGCAGGATGGAG-3') microsatellite loci were cloned and sequenced first in this study, and their respective accession numbers are AM062761 and AM062762. Microsatellites were amplified via the polymerase chain reaction (PCR). Forward primers were labeled with FAM, TAMRA, or HEX fluorescence. The PCR consisted of approximately 1 ng genomic DNA, 2 pmol reverse primer, 2 pmol labeled forward primer, $25 \mathrm{mM}$ dNTP, 0.05 to $0.1 \mathrm{mM}$ $\mathrm{MgCl}_{2}, 10 \times$ buffer, and $0.5 \mathrm{U}$ Taq polymerase (Takara) made up to a $25 \mu \mathrm{l}$ volume with Milli- $Q$ water. Amplification was performed in a PC-960G Microplate Thermal Cycler (Corbett Research) programmed with the following schedule: initial denaturing at $95^{\circ} \mathrm{C}$ for $4 \mathrm{~min}$ followed by 38 cycles of $30 \mathrm{~s}$ each at successive thermal regimes of 94,52 , and $72^{\circ} \mathrm{C}$. Eight microliters of PCR products was precipitated with $95 \%$ alcohol. Semiauto-

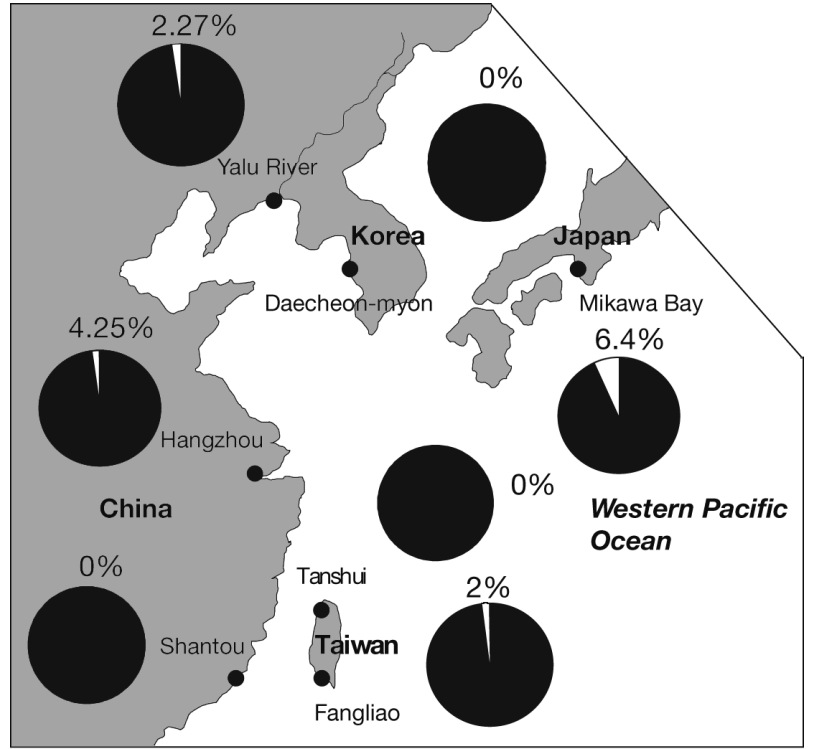

Fig. 1. Anguilla japonica. Sampling localities. The pie charts indicate the percentage of foreign elvers (vagrant)

mated genotyping was performed using a capillary MegaBACE-500 DNA analysis system (Amersham Biosciences). Data were scored by Genetic Profiler software 1.5 (Amersham Biosciences). The sizes of each allele were checked with the naked eye.

Data analysis. The total number of alleles (na), effective number of alleles (ne), and observed $\left(H_{\mathrm{o}}\right)$ and expected $\left(H_{\mathrm{E}}\right)$ heterozygosities were independently calculated for each locus (Yang \& Yeh 1993). Multilocus estimates for each of the 7 samples were calculated as well. Linkage disequilibrium among all pairs of loci and for all samples was determined using Burrows' composite measure and $\chi^{2}$ values (Ohta 1982). Expected genotypic frequencies under random mating were calculated using the algorithm by Levene (1949), and likelihood ratio $\left(\mathrm{G}^{2}\right)$ tests for Hardy-Weinberg equilibrium were performed for each locus.

To examine the relationship among populations, Nei's (1978) unbiased genetic distance (Ds) was computed between all pairs of populations. The original topology of the phylogenic tree was inferred using the UPGMA method based on Ds. One thousand bootstrap re-samplings were used to evaluate support of the data set for the relationships.

Interpopulational genetic differentiation was estimated by calculating the Slatkin's and Wright's fixation indices, $R_{\mathrm{ST}}$ and $F_{\mathrm{ST}}$, based on 2 possible molecular evolution models: the infinite allele model (IAM) and stepwise mutation model (SMM) (Weir \& Cockerham 1984, Raymond \& Rousset 1995). The significance level was adjusted by sequential Bonferroni corrections (Rice 1989). 


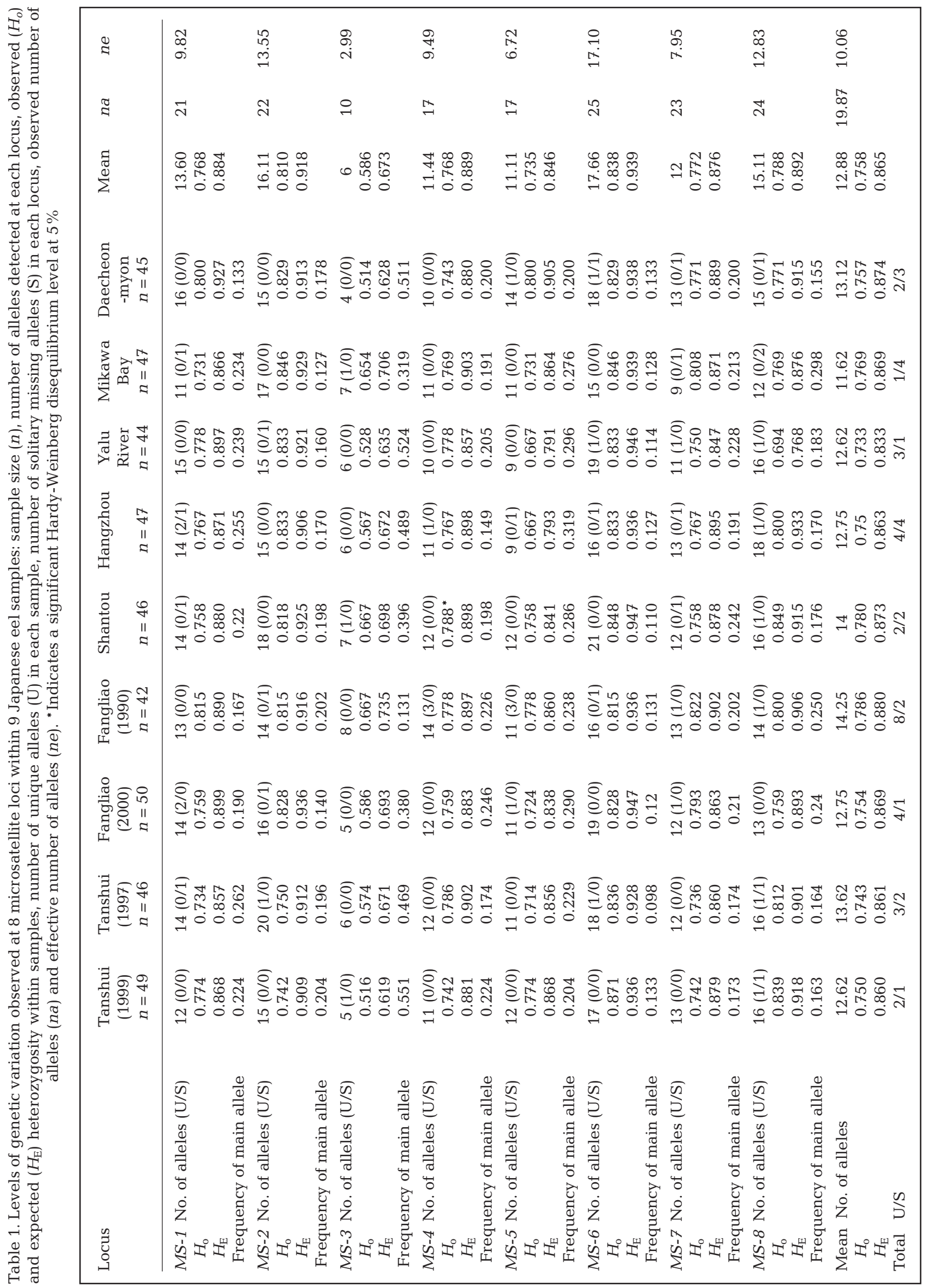


$F$ statistics of spatial samples following the formula of hierarchical level analysis (Weir \& Cockerham 1984) of $F_{\text {IT }}$ and $F_{\text {IS }}$ were calculated using the jackknife over loci to obtain variance estimates with the TPFGA software (Miller 1998). Wright's overall inbreeding coefficient $\left(F_{\mathrm{IT}}\right)$ measures the reduction in heterozygosity of an individual relative to the total population. Additionally, Wright's inbreeding coefficient $\left(F_{\mathrm{IS}}\right)$ measures the reduction in heterozygosity of an individual due to nonrandom mating within its subpopulation. The $95 \%$ confidence intervals (CI) for components of the population structure were determined by jackknifing and 5000 bootstraps conducted over loci using the TFPGA program (Miller 1998). The hierarchical genetic structure was investigated here using analysis of molecular variance (AMOVA, Excoffier et al. 1992) based on an analysis of the variance of genetic distances.

In addition, an assignment test was developed to determine the origin of particular individuals. This test assigned individuals to spatial populations on the basis of their genotypes, while simultaneously estimating population allelic frequencies (Pritchard et al. 2000). The high accuracy of assignments (99\% probability intervals) was analyzed after 30000 burn-in periods with 100000 replications in the 'STRUCTURE' program (Pritchard et al. 2000).

We tested isolation-by-distance (IBD) as an indicator of an emerging population structure by regressing geographic distance on genetic distance $(D s), F_{\mathrm{ST}}$, and $R_{\mathrm{ST}}$. We used Mantel tests for correlation of 2 parameters to examine the significance of the IBD relationships (Mantel 1967).

\section{RESULTS}

\section{Within-population genetic variation}

All 8 microsatellite loci scored among the 9 samples of Anguilla japonica from northeastern Asian countries were highly polymorphic. The number of alleles per locus ranged from $10(M S-3)$ to $25(M S-6)(N=416)$ with an average of 19.87 . The mean number of alleles per locus in each sample ranged from 11.62 (Mikawa Bay) to 14.25 (Fangliao 1990) (Table 1). In total, 29 private and 20 solitary missing alleles (only missing in 1 of all samples) were found in the distributions of the 8 loci. The Japanese eel sampled from Fangliao (1990) seemed to have a greater number of private alleles than did the other samples.

The mean observed heterozygosity over all loci ranged from $0.586 \pm 0.051(\mathrm{SE})(M S-3)$ to $0.838 \pm 0.012$ (MS-6), with an average of $0.758 \pm 0.049$. Samples from Fangliao (1990) exhibited the highest average genetic diversity and had a mean observed heterozygosity of $0.786 \pm 0.034$. The expected heterozygosity ranged from $0.673 \pm 0.031(M S-3)$ to $0.939 \pm 0.005(M S-6)$, with an average of $0.865 \pm 0.052$ (Table 1 ). One of the 8 loci $(M S-4)$ in the Shantou sample showed departure from Hardy-Weinberg equilibrium ( $p<0.05)$, with a significant heterozygote deficiency. Permutation tests for linkage disequilibrium among the 8 loci for all 9 samples revealed only slight disequilibrium for the entire data set. The total variance of disequilibrium $\left(D_{I T}^{2}\right)$ was estimated to be 0.015 , which is a small value.

\section{Among-population genetic variation}

To study evolutionary relationships among spatial and temporal samples, unbiased Nei's (1978) genetic distances were examined and shown to range from approximately 0.040 (Shantou vs. Tanshui 1997) to more than 0.171 (Tanshui vs. Hangzhou) with an average of $0.096 \pm 0.025$.

For further determination of population subdivisions, $F_{\mathrm{ST}}$ and $R_{\mathrm{ST}}$ were used to obtain respective values of -0.002 to 0.019 and -0.009 to 0.104 (Table 2). Samples from Fangliao (1990) exhibited significant genetic differentiation when compared with other samples $\left(F_{\mathrm{ST}}\right.$,

Table 2. Pair-wise $F_{\mathrm{ST}}$ estimates between samples above the diagonal and $R_{\mathrm{ST}}$ estimates below the diagonal. The significance level was adjusted by Bonferroni's correction. ${ }^{*} \mathrm{p}<0.05 ;{ }^{* *} \mathrm{p}<0.01 ;{ }^{\mathrm{a}} \mathrm{p}<0.0014$

\begin{tabular}{|lccccccccc|}
\hline & $\begin{array}{c}\text { Daecheon } \\
\text {-myon }\end{array}$ & $\begin{array}{c}\text { Mikawa } \\
\text { Bay }\end{array}$ & $\begin{array}{c}\text { Yalu } \\
\text { River }\end{array}$ & Hangzhou & Shantou & $\begin{array}{c}\text { Tanshui } \\
(1999)\end{array}$ & $\begin{array}{c}\text { Tanshui } \\
(1997)\end{array}$ & $\begin{array}{c}\text { Fangliao } \\
(2000)\end{array}$ & $\begin{array}{c}\text { Fangliao } \\
(1990)\end{array}$ \\
\hline Daecheon-myon & - & $0.006^{*}$ & 0.005 & 0.002 & $0.006^{* *}$ & $0.009^{* *}$ & $0.009^{* *}$ & $0.007^{*}$ & $0.011^{\mathrm{a}}$ \\
Mikawa Bay & 0.011 & - & $0.008^{* *}$ & $0.007^{*}$ & $0.006^{*}$ & $0.015^{\mathrm{a}}$ & $0.013^{* *}$ & 0.004 & $0.016^{\mathrm{a}}$ \\
Yalu River & 0.007 & $0.048^{\mathrm{a}}$ & - & 0.003 & $0.007^{\mathrm{a}}$ & $0.009^{* *}$ & $0.013^{\mathrm{a}}$ & $0.015^{\mathrm{a}}$ & $0.011^{\mathrm{a}}$ \\
Hangzhou & 0.010 & $0.050^{\mathrm{a}}$ & $0.019^{*}$ & - & $0.013^{\mathrm{a}}$ & $0.012^{\mathrm{a}}$ & $0.019^{\mathrm{a}}$ & $0.009^{*}$ & $0.013^{\mathrm{a}}$ \\
Shantou & -0.002 & 0.016 & $0.023^{* *}$ & 0.005 & - & 0.005 & -0.002 & 0.006 & $0.012^{\mathrm{a}}$ \\
Tanshui (1999) & 0.005 & $0.036^{\mathrm{a}}$ & $0.028^{* *}$ & $0.011^{* *}$ & -0.009 & - & 0.002 & $0.009^{* *}$ & $0.012^{\mathrm{a}}$ \\
Tanshui (1997) & $0.029^{* *}$ & 0.018 & $0.059^{\mathrm{a}}$ & $0.055^{\mathrm{a}}$ & 0.009 & 0.011 & - & $0.010^{* *}$ & $0.013^{\mathrm{a}}$ \\
Fungliao (2000) & 0.017 & $0.022^{*}$ & $0.030^{* *}$ & 0.024 & -0.008 & -0.003 & -0.001 & - & 0.005 \\
Fungliao (1990) & $0.055^{\mathrm{a}}$ & $0.104^{\mathrm{a}}$ & $0.059^{\mathrm{a}}$ & $0.052^{\mathrm{a}}$ & 0.067 & $0.055^{\mathrm{a}}$ & $0.077^{\mathrm{a}}$ & 0.012 & - \\
\hline
\end{tabular}


0.005 to $0.016 ; \mathrm{p}<0.0014)$ except for Fangliao (2000). In Tanshui alone, samples collected in 1999 revealed no significant genetic differentiation from those in 1997 $\left(F_{\mathrm{ST}}=0.002, \mathrm{p}>0.05\right)$. Our overall results indicated moderate genetic divergence between Mikawa Bay and Fangliao $1990\left(R_{\mathrm{ST}}=0.104>0.1, \mathrm{p}<0.0014\right)$, which was the highest among the 9 samples tested (Table 2). Measures of hierarchical genetic structure among spatial populations of Anguilla japonica indicated mean values for $F_{\mathrm{IT}}$ and $F_{\mathrm{IS}}$ of 0.265 and 0.25 , respectively.

The UPGMA tree based on the genetic distance data set showed 2 clades: a low-latitude group (Shantou, Tanshui, and Fangliao) and a high-latitude group (Daecheon-myon, the Yalu River, Hangzhou, and Mikawa Bay) (Fig. 2). Nei's genetic distance ranged from 0.058 to 0.091 (mean $0.072 \pm 0.011$ ) in the highlatitude group, and from 0.040 to 0.127 (mean $0.093 \pm$ 0.028 ) in the low-latitude group (Table 3). The abovetree topology supported by high bootstrap values (100)

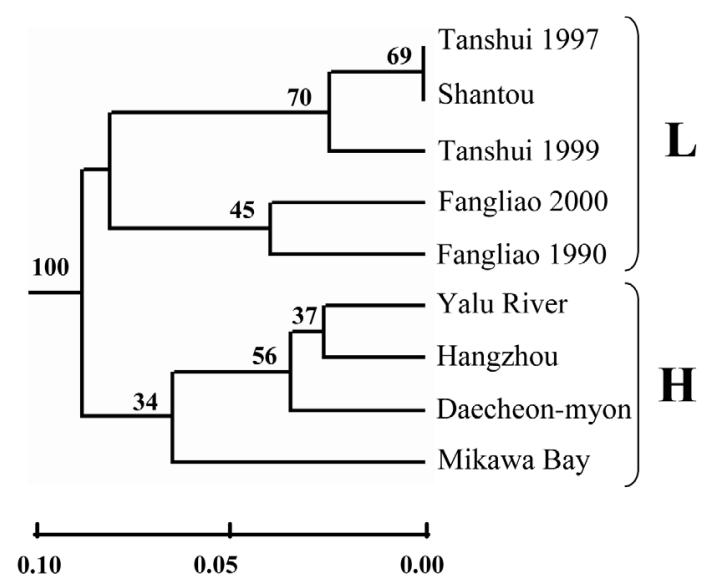

Fig. 2. UPGMA tree drawn using Nei's genetic distance measured for 9 samples of Anguilla japonica. Bootstrap values at each node were obtained by 1000 replicates over loci. Local populations on the tree were grouped into 2 major clades, a low-latitude group (L: Shantou, Tanshui, and Fangliao) and a high-latitude group (H: Mikawa Bay, Daecheon-myon, the Yalu River, and Hangzhou) indicated that the dispersal of Japanese eel elvers to the coast does not occur randomly.

Results of the hierarchical analysis of molecular variance (AMOVA) within and among the 7 spatial populations of Anguilla japonica are shown in Table 4. When genetic variation was tested among the 2 groups (low- and high-latitude groups) from 7 spatial samples, the results of $\Phi_{\mathrm{ct}}=0.009(\mathrm{p}<0.05)$ indicated that $1.95 \%$ of the total genetic variation was partitioned in the among-group category, $95.73 \%$ within populations ( $\mathrm{p}<0.001)$, and $2.32 \%$ among populations within a group. The latter also showed significance $(p<0.001)$ presumably attributable to differences in allelic frequencies among the 7 samples investigated (Table 4).

Genetic distances versus coastal geographical distances for all possible pairwise combinations of the 7 Anguilla japonica samples showed no significant correlation. The Mantel test for correlation of parameters excluded a possible isolation-by-distance principle in the Japanese eel samples $(r=0.123, \mathrm{p}=0.258)$. When genetic distance was used instead of $F_{\mathrm{ST}}$ and $R_{\mathrm{ST}}$ values, we found similar results.

The origin of particular individuals among the 7 spatial samples was calculated. We assigned an accuracy probability of $>0.95$. Among the 328 individuals in the 7 samples, assignment tests indicated that 319 individuals $(97.26 \%)$ obviously belonged to the resident group, while 9 individuals $(2.74 \%)$ were foreign recruits (Fig. 1). Some local samples contained a few recruits from other populations. In the Mikawa Bay sample alone $(n=47)$, a rough estimate of foreignrecruited elvers accounted for a total of $3(6.4 \%)$ which included one from the low-latitude region $(2.13 \%)$ and $2(4.26 \%)$ from the high-latitude region.

\section{DISCUSSION}

As a catadromous fish, the Japanese eel has morenumerous alleles per unit of microsatellite locus (mean,

Table 3. Nei's unbiased genetic distance (below diagonal) of 9 Japanese eel samples

\begin{tabular}{|c|c|c|c|c|c|c|c|c|c|}
\hline & $\begin{array}{l}\text { Daecheon } \\
\text {-myon }\end{array}$ & $\begin{array}{c}\text { Mikawa } \\
\text { Bay }\end{array}$ & $\begin{array}{l}\text { Yalu } \\
\text { River }\end{array}$ & Hangzhou & Shantou & $\begin{array}{c}\text { Tanshui } \\
\text { (1999) }\end{array}$ & $\begin{array}{c}\text { Tanshui } \\
\text { (1997) }\end{array}$ & $\begin{array}{c}\text { Fangliao } \\
\text { (2000) }\end{array}$ & $\begin{array}{c}\text { Fangliao } \\
\text { (1990) }\end{array}$ \\
\hline Daecheon-myon & 0 & & & & & & & & \\
\hline Mikawa Bay & 0.072 & 0 & & & & & & & \\
\hline Yalu River & 0.066 & 0.091 & 0 & & & & & & \\
\hline Hangzhou & 0.060 & 0.086 & 0.058 & 0 & & & & & \\
\hline Shantou & 0.086 & 0.083 & 0.081 & 0.131 & 0 & & & & \\
\hline Tanshui (1999) & 0.096 & 0.105 & 0.089 & 0.116 & 0.078 & 0 & & & \\
\hline Tanshui (1997) & 0.111 & 0.103 & 0.125 & 0.171 & 0.040 & 0.059 & 0 & & \\
\hline Fangliao (2000) & 0.092 & 0.069 & 0.134 & 0.103 & 0.088 & 0.101 & 0.119 & 0 & \\
\hline Fangliao (1990) & 0.108 & 0.995 & 0.099 & 0.105 & 0.119 & 0.111 & 0.127 & 0.086 & 0 \\
\hline
\end{tabular}


Table 4. Hierarchical analysis of molecular variance (AMOVA) within and among 7 populations of Anguilla japonica in northeastern Asia. Two groups including the high- and low-latitudinal groups were inferred from the topological tree. The significance level $(\mathrm{p})$ of the $\Phi$-statistic is based on 1000 permutations. ${ }^{*} \mathrm{p}<0.05 ;{ }^{* *} \mathrm{p}<0.001$

\begin{tabular}{|lccc|}
\hline \multirow{2}{*}{ Variance component } & \multicolumn{2}{c}{ Observation-partition } & \multirow{2}{*}{$\Phi$-statistic } \\
& Variance & Percent of total & \\
\hline Among groups & 0.722 & 1.95 & $\Phi_{\mathrm{ct}}=0.009^{*}$ \\
Among populations/ & 2.522 & 2.32 & $\Phi_{\mathrm{sc}}=0.029^{* *}$ \\
within groups & 72.715 & 95.73 & $\Phi_{\mathrm{st}}=0.036^{* *}$ \\
Within populations & & & \\
\hline
\end{tabular}

netic differentiation indices obtained in this study support the non-panmictic hypothesis in the Japanese eel. There may have been strong inbreeding within populations $\left(F_{\text {IT }}=0.265\right.$ and $\left.F_{\text {IS }}=0.25\right)$. The magnitude of spatial differentiation in Japanese eels $\left(F_{\mathrm{ST}}=\right.$ -0.002 to 0.019 , mean 0.009 ) is higher than that of the European eel $(0.0017$ in Daemen et al. 2001; 0.004 in Wirth \& Bernatchez 2001).

Since the AMOVA $\Phi$-statistic value of $1.95 \%(p<0.05)$ provides a certain

19.87) than do anadromous (mean $=10.8$ ) and freshwater fishes (mean $=9.1$ ), but slightly fewer than do marine fishes $($ mean $=19.9)$ (DeWoody \& Avise 2000). The mean number of alleles/locus/sample varied between 11.62 (Mikawa Bay) and 14.25 (Fangliao) (mean $=12.88)$ in Japanese eels, and 9.6 and 12.4 (Daemen et al. 2001) or 12.9 and 21.2 (Wirth \& Bernatchez 2001) in European eels. These values are all within the range common for teleosts. These results imply a progressive change in genetic variability among freshwater, anadromous, catadromous, and marine fishes. Although the freshwater eel is categorized as a catadromous fish, its genetic diversity is close to that of marine fishes.

The average observed heterozygosity over 8 microsatellite loci ranged from 0.586 to 0.838 in Japanese eels, and 0.278 to 0.737 (Daemen et al. 2001) or 0.835 to 0.895 (Wirth \& Bernatchez 2001) in European eels. Only 1 locus showed significant departure from Hardy-Weinberg equilibrium in 1 sample. This may have been associated with the null allele effect, where the increase in homozygosity may have been caused by a failure of allelic amplification due to a mutation in the primer region. Among the 8 polymorphic microsatellite loci used, locus $M S$-3 exhibited the lowest heterozygosity value and allele number. There were fewer repetitions (6 to 12) at the MS-3 locus than at other loci, implying a correlation of repetition number with increasing allele number and genetic diversity (Weber 1990).

\section{Population structure}

Several pieces of evidence support the population subdivision of Japanese eels using the highly resoluble microsatellites as gene markers. The genetic differentiation indices $\left(F_{\mathrm{ST}}\right.$ and $\left.R_{\mathrm{ST}}\right)$ indicated a weak but significant spatial divergence among samples. Recent studies have argued for a random mating system in Anguilla eels, but Wirth \& Bernatchez (2001) have a different view of the European eel. The significant ge- degree of genetic variance between the 2 groups (low and high latitudes), Japanese eel populations are clearly distinguished into a 2-group model, as represented by the general profile shown in the relevant tree topology (Fig. 2). As to their life history, aging, based on otoliths at metamorphosis, is somewhat postponed in the high-latitude group compared to the lowlatitude group (Cheng \& Tzeng 1996).

Our results thus clearly show that a weak but highly significant genetic structure exists in the Japanese eel. We wanted to determine which one of the population models best explains the observed genetic structure. The timing of metamorphosis of a leptocephalus and transportation by the Kuroshio Current were considered to be important factors determining the ultimate destination of eels. The eel has a lengthy leptocephalus stage during the oceanic passive migration, and there is a geographic cline in age at metamorphosis that increases from south to north (Cheng \& Tzeng 1996). Variations in the duration of the larval stage are an important factor in determining the distribution of a fish. In the absence of a suitable habitat for settlement, larvae may delay metamorphosis, a delay which may last for months in several species of invertebrates (Richmond 1985). The age at metamorphosis and the lengthy duration of the leptocephalus stage are important factors determining the long-distance dispersal of the Japanese eel.

Results from this study in conjunction with previous studies (Cheng \& Tzeng 1996, Tseng et al. 2003) provide new elements that can refine the current hypotheses including isolation by distance (Maes \& Volckaert 2002), spatial differentiation (Ishikawa et al. 2004), temporal reproductive separation (Cheng \& Tzeng 1996), and some combination of these.

The first isolation-by-distance hypothesis states that differentiation contributes to genetic structuring at the spawning grounds. The hydrogeographical structure of the spawning area potentially limits contact between spawning groups: a scenario detected using both microsatellite and allozymic markers of Anguilla anguilla (Wirth \& Bernatchez 2001, Maes \& Volckaert 2002). Each 
species has its own particular genetic structures based on its own adaptations to the unique hydrographic systems of the respective Pacific and Atlantic habitats. Interspecific differences in genetic structure result from variations in systems of ocean currents and evolutionary histories. When examining the Mantel relation test, we could largely reject the isolation-by-distance hypothesis in the Japanese eel, although the European eel conforms to this hypothesis (Wirth \& Bernatchez 2001, Maes \& Volckaert 2002). Inconsistencies with the isolation-bydistance model are evidenced by greater divergences between closely spaced sites. This may be because different groups of elvers passively drift to destinations, a process dependent on the complicated sub-current systems of the northwestern Pacific Ocean.

The second hypothesis states that spatial differentiation contributes to genetic structuring at a particular migratory loop: maturing adults may spawn within their subpopulation in a specific area. The existence of 5 geographic populations of Anguilla marmorata can be understood by examining the close correspondence of their geographic ranges with the oceanographic divisions of major upper-water masses characterized by salinity and temperature (Ishikawa et al. 2004). The life cycle of each of the 5 populations should be completed within each oceanic division. It can be concluded, therefore, that the general rule of population structure of anguillid eels should be regarded as a 'one-population/one-migration loop within one oceanic division' (Ishikawa et al. 2004). However, $A$. japonica and A. marmorata have different life history patterns. A. marmorata differs markedly from temperate anguillid eels in having distinct spawning and recruitment seasons.

The third hypothesis suggested by Chan et al. (1997) states that Japanese eel groups of spawning adults originating from different regions are temporally isolated, and this persists from year to year. Offspring fitness increases when individuals stay in close spatiotemporal proximity to their own 'clutch', and offspring return to the habitat of their ancestors due to the system of currents. Tseng et al. (2003) examined temporal genetic variations in Japanese eels in northern Taiwan from 1997 to 1999. The results indicated no significant differentiation among temporal samples. In this study, we analyzed temporal genetic variations from samples of Tanshui in 1997 and 1999 and Fangliao in 1990 and 2000. Lower genetic distances were presented between those respective samples. These results support offspring returning to the habitat of their ancestors.

Nevertheless, the larval ecology of the Japanese eel is still poorly known, because of a lack of significant genetic continuity among elvers. Leptocephali of the low-latitude group rarely succeed in drifting to farther destinations due to the postponement of metamorphosis as a result of nutrient shortages. Vagrant larvae may reach the coasts of Japan and northern China with the aid of the speedy Kuroshio Current ( 2 to 3 knots or 77 to $116 \mathrm{~km} \mathrm{~d}^{-1}$ ) after it passes near Taiwan (Nitani 1972). Although the Japanese eel is known to be composed of 2 subgroups, our study does not fully support the isolated migration model. Geographical divergences observed among sites of the present study may be the result of physiological and environmental influences on larval dispersion. For example, $2.27 \%$ of the sample in the Yalu River consisted of foreign-recruited elvers (Fig. 1). This suggests that ecological processes inferred by the member-vagrant hypothesis with some degree of exchange between neighboring-populations (metapopulation) explain the present and previous results of the eel's population genetic structure. The member-vagrant model may be a primary factor controlling population genetic diversity in Japanese eel elvers. The population structure of the Japanese eel, however, still remains genetically diverse.

\section{Management}

Serious declines in fish stocks in many parts of the world over the past 2 to 3 decades and the collapse of several economically important fisheries have driven many fisheries organizations to reexamine the principles they apply to fisheries management (Richards \& Maguire 1998). The gradually decreasing population size of Anguilla freshwater eels may be related to several causes, e.g. overfishing of elvers since the 1960s, destruction of adult eel habitats in rivers, and population declines due to long-term climatic fluctuations since the Holocene (Tseng et al. 2003, Wirth \& Bernatchez 2003), and suggest that effective management should pay attention to these phenomena. Effective future conservation should incorporate issues of scientific research, legislation, and management. The observed distribution of genotypes in this study are indicative of non-random mating and restricted gene flow among eels from different sampled locations, and are at odds with the concept of a single panmictic stock. In addition to the above, there are many other uncertainties pertaining to the biology and life cycle of the eel. It is thought that this phase which is principally being driven by long-term oceanic and climate changes may be impacting the recruitment of anguillid species throughout the Northern Hemisphere. While such changes may be beyond our control, management actions may be required to reduce exploitation or enhance stocks to counteract the effects of this natural phenomenon. This is particularly pertinent to the management of elver fisheries in parts of the northwestern Pacific Ocean. As to concerns of scientific 
research, we have delineated 2 management units (high- and low-latitudinal groups) for the Japanese eel, in order to measure population demographics. A forthcoming work will focus on ecological investigations within these geographic regions and propose constructive polices for the control of overfishing of both elvers and adults.

\section{Microsatellite diversity}

The resolution of genetic diversity varies with the genetic markers used. Genetic diversity derived from microsatellite loci of Japanese eels was higher than that from analysis of mitochondria or proteins. Previous studies of genetic differences with the mitochondrial control region revealed similar genetic and haplotypic diversities in Japanese eels ( 0.16 to $2.60 \%$ and $96 \%$ ) as in sardines (Sardina and Sardinops, 1 to $3 \%$ and 96 to $100 \%$, respectively) (Sang et al. 1994, Bowen \& Grant 1997, Ishikawa et al. 2001). Thus, in rapidly expanding populations, low genetic and high haplotypic diversities may result in the accumulation of mutations leading to an increase in the number of haplotypes (Rogers \& Harpending 1992). For the Japanese eel, however, population demographics indicate historical declines (Tseng et al. 2003). The high haplotypic diversity probably resulted from the large population size of Japanese eel and the small sample size in mtDNA studies. Isozymic electrophoresis of metabolic IDHP and PGDH loci reveals a slight geographical cline even under such a low Nei's (1972) genetic distance of 0.003 to 0.02 (mean 0.013) (Chan et al. 1997). Nevertheless, Nei's (1978) genetic distances of 0.04 to 0.171 (mean $0.096 \pm$ 0.025) obtained from the present study represent higher genetic variability at microsatellite loci than those determined using mitochondrial and protein studies. There are 2 reasons for such a discrepancy. Protein electrophoresis can detect only one-third of the amino acid substitutions, but microsatellites can resolve many more repetitive sequence variations. In addition, microsatellites have higher mutation rates than mtDNA (Dallas 1992).

\section{Conclusions}

The population genetic structure of the Japanese eel examined based on microsatellite loci exhibited slight but significant genetic differentiation among geographic samples. The Japanese eel can be divided into a high-latitude (Daecheon-myon, the Yalu River, Hangzhou, and Mikawa Bay) and a low-latitude (Shantou, Tanshui, and Fangliao) group based on tree topology and AMOVA analysis. The ecological migration patterns of juveniles fit the member-vagrant model within the metapopulation. The genetic evidence including slight but significant genetic differentiation and the topology of the phylogenetic tree confirm that the Japanese eel does not have a panmictic population structure in the northwestern Pacific Ocean.

Current world fisheries have been threatened by overfishing and habitat destruction through water extraction, dam construction, and industrial pollution. Management efforts are extremely important for commercial fisheries, which through overharvesting can become economically unviable well before the exploited species becomes threatened with biological extinction. We propose that the eel populations in the northwestern Pacific Ocean can be classified into 2 management groups based on the divergence in nuclear allele frequencies.

Acknowledgements. The authors express their gratitude to Ms. H.Y. Teng and Drs. C.W. Chang and Y.T. Wang for collecting specimens from Taiwan. Special thanks are due to Profs. Y.H. Xie and H.P. Oka, respectively, for providing samples from China and Japan. We are indebted to Drs. C.A. Chen and H.Y. Wang for valuable advice and for reviewing the manuscript. Research funding was provided to S.C.L. by the Institute of Zoology, Academia Sinica, Taipei, Taiwan.

\section{LITERATURE CITED}

Avise JC (2003) Catadromous eels of the North Atlantic: a review of molecular genetic findings relevant to natural history, population structure, speciation, and phylogeny. In: Aida K, Tsukamoto K, Yamauchi K (eds) Eel biology. Springer-Verlag, Tokyo, p 31-48

Avise JC, Helfman GS, Saunders NC, Hales LS (1986) Mitochondrial DNA differentiation in North Atlantic eels: population genetic consequences of an unusual life history pattern. Proc Natl Acad Sci USA 83:4350-4353

Bernatchez L, Martin S (1996) Mitochondrial DNA diversity in anadromous rainbow smelt, Osmerus mordax Mitchill: a genetic assessment of the member-vagrant hypothesis. Can J Fish Aquat Sci 53:424-433

Bowen BW, Grant WS (1997) Phylogeography of the sardines (Sardinops spp.): assessing biogeographic models and population histories in temperate upwelling zones. Evolution 51:1601-1610

Chan IKK, Chan DKO, Lee SC, Tsukamoto K (1997) Genetic variability of the Japanese eel Anguilla japonica (Temminck \& Schlegel) related to latitude. Ecol Freshw Fish 6:45-49

Cheng PW, Tzeng WN (1996) Timing of metamorphosis and estuarine arrival across the dispersal range of the Japanese eel Anguilla japonica. Mar Ecol Prog Ser 131:87-96

Daemen E, Cross T, Ollevier F, Volckaert FAM (2001) Analysis of the genetic structure of European eel (Anguilla anguilla) using microsatellite DNA and mtDNA markers. Mar Biol 139:755-764

Dallas JF (1992) Estimation of microsatellite mutation rates in recombinant inbred strains of mouse. Mamm Genom 5: 32-38

De Ligny W, Pantelouris EM (1973) Origin of the European eel. Nature 246:518-519 
DeWoody JA, Avise JC (2000) Microsatellite variation in marine, freshwater and anadromous fishes compared with other animals. J Fish Biol 56:461-473

Excoffier L, Smouse PE, Quattro JM (1992) Analysis of molecular variance inferred from metric distances among DNA haplotypes: application to human mitochondrial DNA restriction data. Genetics 131:479-491

Fortier L, Gagne JA (1990) Larval herring (Clupea harengus) dispersion, growth, and survival in the St. Lawrence Estuary: match/mismatch or membership/vagrant. Can J Fish Aquat Sci 47:1898-1912

Gaggiotti OE (1996) Population genetic models of source-sink metapopulations. Theor Popul Biol 50:178-208

Hanski I (1994) A practical model of metapopulation dynamics. J Anim Ecol 63:151-162

Iles TD, Sinclair M (1982) Atlantic herring: stock discreteness and abundance. Science 215:627-633

Ishikawa S, Aoyama J, Tsukamoto K, Nishida M (2001) Population structure of the Japanese eel Anguilla japonica as examined by mitochondrial DNA sequencing. Fish Sci 67: $246-253$

Ishikawa S, Tsukamoto K, Nishida M (2004) Genetic evidence for multiple geographic populations of the giant mottled eel Anguilla marmorata in the Pacific and Indian Oceans. Ichthyol Res 51:343-353

Kocher TD, Thomas WK, Meyer A, Edwards SV, Pabo S, Villablabca FX, Wilson AC (1989) Dynamics of mitochondrial DNA evolution in animals: amplification and sequencing with conserved primers. Proc Natl Acad Sci USA 86: 6196-6200

Levene H (1949) On a matching problem in genetics. Ann Math Stat 20:91-94

Lintas C, Hirano J, Archer S (1998) Genetic variation of the European eel Anguilla anguilla. Mol Mar Biol Biotech 7: 263-269

Maes GE, Volckaert FAM (2002) Clinal genetic variation and isolation by distance in the European eel Anguilla anguilla (L.). Biol J Linn Soc 77:509-521

Mantel N (1967) The detection of disease clustering and a generalized regression approach. Cancer Res 27:209-220

Miller MP (1998) Tools for population genetic analysis (TFPGA) 1.3: a Windows program for analysis of allozyme and molecular population genetic data. Available at http://bioweb.usu.edu/ mpmbio/index.htm

Nei M (1972) Genetic distance between populations. Am Nat 106:283-292

Nei M (1978) Estimation of average heterozygosity and genetic distance from a small number of individuals. Genetics 89:583-590

Nitani H (1972) Beginning of the Kuroshio. In: Stommel H, Yoshida K (eds) Kuroshio - its physical aspects. University Tokyo Press, Tokyo, Japan, p 129-163

Ohta T (1982) Linkage disequilibrium due to random drift in infinitely subdivided populations. Proc Natl Acad Sci USA 79:1940-1944

Editorial responsibility: Otto Kinne (Editor-in-Chief), Oldendorf/Luhe, Germany
Pritchard JK, Stephens M, Donnelly P (2000) Inference of population structure using multilocus genotype data. Genetics 155:945-959

Raymond M, Rousset F (1995) An exact test for population differentiation. Evolution 49:1280-1283

Rice WR (1989) Analyzing tables of statistical tests. Evolution 43:223-225

Richards LL, Maguire JJ (1998) Recent international agreements and the precautionary approach: new directions for fisheries management science. Can J Fish Aquat Sci 55: $1545-1552$

Richmond RH (1985) Reversible metamorphosis in coral planula larvae. Mar Ecol Prog Ser 22:181-185

Rogers AR, Harpending H (1992) Population growth makes waves in the distribution of pairwise genetic differences. Mol Biol Evol 9:552-569

Sambrook J, Fritsch EF, Maniatis T (1989) Molecular cloning, a laboratory manual, 2nd ed. Cold Spring Harbor Laboratory Press, New York

Sang TK, Chang HY, Chen CT, Hui CF (1994) Population structure of the Japanese eel Anguilla japonica. Mol Biol Evol 11:250-260

Sinclair M, Iles TD (1988) Population richness of marine fish species. Aquat Liv Resour 1:71-83

Sjögren-Gulve P (1994) Distribution and extinction patterns within a northern metapopulation case of the pool frog, Rana lessonae. Ecology 75:1357-1367

Tesch FW (1977) The eel: biology and management of Anguillid eels. Chapman \& Hall, London

Tseng MC, Chen CA, Kao HW, Tzeng WN, Lee SC (2001) Polymorphisms of GA/GT microsatellite loci from Anguilla japonica. Mar Biotech 3:275-280

Tseng MC, Tzeng WN, Lee SC (2003) Historical decline in the Japanese eel Anguilla japonica in northern Taiwan inferred from genetic variations. Zool Stud 42:556-563

Tsukamoto K (1992) Discovery of the spawning area for Japanese eel. Nature 356:789-791

Tzeng WN (1985) Immigration timing and activity rhythms of the eel, Anguilla japonica, elvers in the estuary of northern Taiwan, with emphasis on environmental influences. Bull Jpn Soc Fish Oceanogr 47/48:11-28

Weber JL (1990) Informativeness of human $(d C-d A) n \times(d G-$ dT)n polymorphisms. Genomics 7:524-530

Weir BS, Cockerham CC (1984) Estimating F-statistics for the analysis of population structure. Evolution 38:1358-1370

Wirth T, Bernatchez L (2001) Genetic evidence against panmixia in the European eel. Nature 409:1037-1040

Wirth T, Bernatchez L (2003) Decline of North Atlantic eels: a fatal synergy. Proc R Soc Lond 270:681-688

Yang RC, Yeh FC (1993) Multilocus structure in Pinus contoria Dougl. Theor Appl Genet 87:568-576

Yu HT, Lee YJ, Huang SW, Chiu TS (2002) Genetic analysis of the populations of Japanese anchovy (Engraulidae: Engraulis japonicus) using microsatellite DNA. Mar Biotech 4:471-479

Submitted: November 11, 2004; Accepted: June 26, 2005

Proofs received from author(s): November 16, 2005 